\title{
A TETRASOMIC MOSAIC IN THE GERM LINE OF CHORTHIPPUS PARALLELUS
}

\author{
G. M. HEWITT \\ Agricultural Research Council Unit of Biometrical Genetics, Genetics \\ Department, The University of Birmingham

\section{INTRODUCTION} \\ Received Io.v.63
}

DURING the study of the population cytology of British grasshoppers a single male Chorthippus parallelus was found which proved to be a chromosomal mosaic. About a quarter of the meiotic cells were normal, having eight pairs of autosomes and a single $X$ univalent (John, Lewis and Henderson, I96o). The remainder were tetrasomic for one of the large acrocentrics. There have been few detailed analyses of the influence of additional chromosome material on the chiasma forming properties of cells (Mather, 1939). In Chorthippus it is possible to identify each bivalent individually at first metaphase, and this, coupled with the fact that the abnormal individual is mosaic, allows a precise analysis of this type of problem, using the normal cells as a control.

\section{MATERIAL AND TECHNIQUE}

The mosaic individual was one of 22 young male imagines taken near Ashurst Halt, New Forest, England, during the 1962 meiotic season. The testes were removed by vivisection, fixed in acetic-alcohol $1: 3$, and subsequently squashed in acetic orcein. A number of the follicles were treated individually to determine the pattern of mosaicism ; the remainder were squashed in bulk and yielded five preparations (table 1 ).

\section{OBSERVATIONS}

The preparations were used to compare the chiasma frequency of disomic (normal) and tetrasomic cells both at diplotene and metaphase I. The cell numbers are summarised in table 1. At diplotene individual bivalents cannot always be distinguished, consequently chiasma frequencies were recorded for the size groups within the complement ( 3 long: 4 medium:I short). At metaphase I, however, where the positions of the centromeres are apparent, it is possible to assess the chiasma frequency of each bivalent individually.

In all the tetrasomic cells examined the additional chromosomes were present as an extra bivalent. In no case was a multivalent formed. Despite this absence of multivalents there is no reason to believe that the extra pair of chromosomes is not homologous with the $\mathrm{M}_{4}$, for in polyploid cells of this genus multivalent formation has only been observed in the $\mathrm{L}$ type chromosomes (e.g. fig. 59, John and Henderson, 1962).

The possibility that the extra chromosomes are B-chromosomes has been discounted on the following grounds:

(i) B-chromosomes are usually smaller than normal members of the complement. This is not an invariable rule but it is a useful one. 
(ii) No B-chromosomes have ever been reported in a species of Chorthippus. Barker ( 1960 ) has claimed their occurrence in Myrmeleotetix maculatus, though even here they characterise only certain populations and only some individuals in such populations. In such cases, however, they are present in all follicles within the individual.

TABLE I

A summary of numbers of cells scored in the five slides made from the germ line mosaic. The two samples from slides 3 and 5 are from quite distinct areas

\begin{tabular}{|c|c|c|c|c|}
\hline \multirow{2}{*}{ Slide no. } & \multicolumn{2}{|c|}{ Disomic } & \multicolumn{2}{|c|}{ Tetrasomic } \\
\hline & Diplotene & Metaphase I & Diplotene & Metaphase I \\
\hline $\begin{array}{l}\text { I } \\
2\left\{\begin{array}{l}\text { area a } \\
\text { area b }\end{array}\right. \\
4\left\{\begin{array}{l}\text { area a } \\
\text { area b }\end{array}\right.\end{array}$ & $\begin{array}{l}20 \\
\cdots \\
\cdots \\
\cdots \\
\cdots \\
\cdots \\
\cdots\end{array}$ & $\begin{array}{l}10 \\
10 \\
\cdots \\
\cdots \\
\cdots \\
\cdots \\
\cdots\end{array}$ & $\begin{array}{l}\ldots \\
20 \\
\cdots \\
\ldots \\
\ldots \\
10 \\
10\end{array}$ & $\begin{array}{l}\ldots \\
\ldots \\
20 \\
10 \\
10 \\
10 \\
10\end{array}$ \\
\hline \multirow[t]{2}{*}{ Totals } & 20 & 20 & $4^{\circ}$ & 60 \\
\hline & \multicolumn{2}{|c|}{40} & \multicolumn{2}{|c|}{100} \\
\hline
\end{tabular}

(iii) The germ line of this anomalous individual of $C h$. parallelus was atypical not merely in respect of the extra autosomes, but also in the presence of extra X-chromosomes in several of the cells (fig. 5). This applies to both disomic and tetrasomic cell types and clearly indicates non-disjunction in the germ line.

The extra chromosomes were indistinguishable in size from the $\mathbf{M}_{4}$. In about 90 per cent. of the diplotene cells, however, one of the $\mathbf{M}_{4}$-type bivalents was precocious (figs. 2-4). This is not a normal aspect of $M_{4}$ behaviour, though the $M_{6}$ bivalent is invariably precocious. Chiasma analysis reveals no difference in either frequency or localisation pattern between the two $\mathrm{M}_{4}$-type bivalents, and it is not possible to determine whether the heteropycnotic bivalent consistently represents the same chromosomes. Certainly the heterochromatinisation of one of the two X-chromosomes in female mammals is a random phenomenon: the paternally derived one being heteropycnotic in some cells, the maternally derived one in others (Lyon, I96I). Presumably this also holds where extra $\mathrm{X}$-chromosomes are present in sex aneuploids.

The tetrasomic condition must, in this case, have arisen by a process of double non-disjunction of the $\mathrm{M}_{4}$ at mitosis. Comparable situations have been reported in single cells of Schistocerca gregaria (John and Naylor, 1961) and Pholidoptera griseoaptera (Henderson, I96I). Single follicle analysis reveals the interesting fact that individual follicles are homogeneous in their chromosome constitutions.

Chiasma scores for disomic and tetrasomic cells within the mosaic 
at both diplotene and metaphase I are summarised in tables 2 and 3 respectively. As well as the obvious differences between disomic and tetrasomic cells, there is clearly considerable variation between different slides, between different samples from distinct areas on

TABLE 2

Summary of disomic and tetrasomic diplotene scores

\begin{tabular}{|c|c|c|c|c|c|c|c|c|}
\hline \multirow{2}{*}{$\begin{array}{c}\text { Cell } \\
\text { condition }\end{array}$} & \multirow{2}{*}{ Slide no. } & \multicolumn{3}{|c|}{ Chromosome class } & \multirow{2}{*}{$\mathrm{M}_{4}$} & \multirow{2}{*}{$\begin{array}{c}\text { Total } \\
\text { chiasmata }\end{array}$} & \multirow{2}{*}{$\begin{array}{l}\text { Total } \\
\text { cells }\end{array}$} & \multirow{2}{*}{ Mean } \\
\hline & & Long & Medium & Short & & & & \\
\hline Disomic & I & I 78 & 92 & 20 & 30 & 290 & 20 & 14.50 \\
\hline Tetrasomic & $5\left\{\begin{array}{l}\text { area a } \\
\text { area b }\end{array}\right.$ & $\begin{array}{r}177 \\
98 \\
94\end{array}$ & $\begin{array}{r}126 \\
61 \\
63\end{array}$ & $\begin{array}{l}20 \\
20 \\
20\end{array}$ & $\begin{array}{l}62 \\
26 \\
29\end{array}$ & $\begin{array}{l}324 \\
169 \\
167\end{array}$ & $\begin{array}{l}20 \\
10 \\
10\end{array}$ & $\begin{array}{l}16 \cdot 20 \\
16 \cdot 90 \\
16 \cdot 70\end{array}$ \\
\hline
\end{tabular}

TABLE 3

Summary of disomic and tetrasomic metaphase I scores

\begin{tabular}{|c|c|c|c|c|c|c|c|c|}
\hline \multirow{2}{*}{$\begin{array}{c}\text { Cell } \\
\text { condition }\end{array}$} & \multirow{2}{*}{ Slide no } & \multicolumn{4}{|c|}{ Chromosome type } & \multirow{2}{*}{$\begin{array}{c}\text { Total } \\
\text { chiasmata }\end{array}$} & \multirow{2}{*}{$\begin{array}{l}\text { Total } \\
\text { cells }\end{array}$} & \multirow{2}{*}{ Mean } \\
\hline & & $\mathrm{L}_{1}$ & $\mathrm{~L}_{2}$ & $\mathrm{~L}_{3}$ & $M_{4}$ & & & \\
\hline Disomic & $\begin{array}{l}1 \\
2\end{array}$ & $\begin{array}{l}37 \\
34\end{array}$ & $\begin{array}{l}29 \\
30\end{array}$ & $\begin{array}{l}25 \\
24\end{array}$ & $\begin{array}{l}18 \\
16\end{array}$ & $\begin{array}{l}\text { I } 51 \\
\text { I } 44\end{array}$ & $\begin{array}{l}\text { Io } \\
\text { Io }\end{array}$ & $\begin{array}{l}15 \cdot 10 \\
14.40\end{array}$ \\
\hline Tetrasomic & $\begin{array}{l}3\left\{\begin{array}{l}\text { area a } \\
\text { area b }\end{array}\right. \\
4\left\{\begin{array}{l}\text { area a } \\
\text { area b }\end{array}\right.\end{array}$ & $\begin{array}{l}66 \\
35 \\
3^{6} \\
37 \\
3^{8}\end{array}$ & $\begin{array}{l}58 \\
31 \\
30 \\
36 \\
32\end{array}$ & $\begin{array}{l}45 \\
24 \\
22 \\
28 \\
30\end{array}$ & $\begin{array}{l}6 \mathrm{I} \\
28 \\
26 \\
28 \\
29\end{array}$ & $\begin{array}{l}313 \\
158 \\
155 \\
172 \\
\text { I } 71\end{array}$ & $\begin{array}{l}20 \\
10 \\
10 \\
10 \\
10\end{array}$ & $\begin{array}{l}15 \cdot 65 \\
15 \cdot 80 \\
15 \cdot 50 \\
17 \cdot 20 \\
17 \cdot 10\end{array}$ \\
\hline
\end{tabular}

the same slide, and between stages. To assess the relative importance of these several variables an analysis of variance was performed on a series of samples of ten cells each, chosen as follows:

\begin{tabular}{|c|c|c|c|c|}
\hline \multirow{2}{*}{ Slide no. } & \multicolumn{2}{|c|}{ Disomic } & \multicolumn{2}{|c|}{ Tetrasomic } \\
\hline & Diplotene & Metaphase I & Diplotene & Metaphase I \\
\hline $\begin{array}{l}\text { I } \\
2 \\
5 \text { a } \\
3\{\text { area a } \\
4\end{array}$ & $\begin{array}{l}\text { 10 } \\
\ldots \\
\cdots \\
\cdots \\
\cdots \\
\cdots\end{array}$ & $\begin{array}{l}\text { 10 } \\
\text { 10 } \\
\cdots \\
\cdots \\
\cdots \\
\cdots \\
\end{array}$ & $\begin{array}{l}\ldots \\
\text { Io } \\
10 \\
\ldots \\
\ldots \\
\cdots\end{array}$ & $\begin{array}{l}\cdots \\
\ldots \\
10 \\
10 \\
10 \\
10\end{array}$ \\
\hline \multirow[t]{2}{*}{ Totals } & 10 & 20 & 20 & $4^{\circ}$ \\
\hline & \multicolumn{2}{|c|}{30} & \multicolumn{2}{|c|}{60} \\
\hline
\end{tabular}


Where more than ten cells had been scored for a particular slide and stage (see table I) only the first ten were used for this analysis. Since cells are not scored in any particular sequence this may be taken as representing a random sample.

There are three main effects in this analysis:

I. Differences between disomic and tetrasomic.

2. Differences between diplotene and metaphase I.

3. Differences between samples.

The sum of the squares for the first two effects were obtained by comparing the totals of all disomic and tetrasomic cells, and all diplotene and metaphase I cells respectively. Since, however, "samples" is not orthogonal to these other two items, it was obtained by comparing replicate samples within the same stage and within the disomic or the tetrasomic class. This yields five comparisons with five degrees of freedom. The results of this analysis are summarised in table 4 .

\section{TABLE 4}

Analysis of variance between di- and tetrasomic cells at diplotene and first metaphase based on nine samples each of ten cells from six areas. (See Table on page 507)

\begin{tabular}{|c|c|c|c|c|c|c|}
\hline Item & & $\mathrm{dF}$ & SS & MS & VR & $\mathbf{P}$ \\
\hline $\begin{array}{l}\text { Disomic } v \text {. Tetrasomic } \\
\text { Diplotene } v \text {. Metaphase } \\
\text { Samples } \\
\text { Remainder }\end{array}$ & $\begin{array}{l}\cdot \\
\dot{5} \\
\dot{5}\end{array}$ & $\begin{array}{r}I \\
I \\
5 \\
82\end{array}$ & $\begin{array}{r}33.799 \\
6.050 \\
13.150 \\
105.401\end{array}$ & $\begin{array}{r}33 \cdot 799 \\
6 \cdot 050 \\
2 \cdot 630 \\
1 \cdot 285\end{array}$ & $\begin{array}{r}26 \cdot 303 \\
4 \cdot 708 \\
2 \cdot 047 \\
\cdots\end{array}$ & $\begin{array}{c}<0.1 \% \\
\bumpeq 5 \% \\
5 \%-10 \% \\
\ldots\end{array}$ \\
\hline Total & . & 89 & 158.400 & $\ldots$ & $\cdots$ & $\ldots$ \\
\hline
\end{tabular}

The comparison of disomic versus tetrasomic is clearly significant, but items 2 and 3 are of borderline significance only. Since item 2 is no more significant than item 3 there is no more difference between the diplotene and metaphase I samples than there is between any two diplotene or any two metaphase samples. We can, therefore, probably disregard the different stages at which these cells were scored.

Examination of the data suggests that the tetrasomic cells differ more between samples than the disomic ones, the range of sample means being $15.50-17.20$ in the tetrasomic and $14.40-15.10$ in the disomic. The variance of the tetrasomic samples is also higher than that of the disomic samples, 5.32 for $7 \mathrm{dF}$ versus $\mathrm{I} \cdot 55$ for $2 \mathrm{dF}$ respectively. The ratio of the variances is not significant ( $P=20$ per cent.) but this is hardly likely since there are so few degrees of freedom. From our observations in this unit the variance between samples in normal individuals is of the same order as the variance of disomic samples. An analysis of items 2, 3 and 4 in table 4 was therefore carried out on all the tetrasomic cells which had been analysed (see tables 2 and 3 ); 
the results are shown in table 5. This shows that samples differ significantly whereas the stage difference is not significant. Thus while different samples of disomic cells are similar, different samples of the tetrasomic ones are not.

TABLE 5

Analysis of variance of tetrasomic cells from forty diplotene and sixty first metaphase. (See Table 1)

\begin{tabular}{|c|c|c|c|c|c|c|}
\hline \multicolumn{2}{|r|}{ Item } & $\mathrm{dF}$ & SS & MS & VR & $\mathbf{P}$ \\
\hline Diplotene $v$ & Metaphase & I & $2 \cdot 04$ & $2 \cdot 94^{\circ}$ & ... & Not significant \\
\hline Samples & . & 6 & $34 \cdot 30$ & $5 \cdot 717$ & $4 \cdot 004$ & $0.1 \%$ \\
\hline Remainder & . & 92 & $13 x \cdot 35$ & $I \cdot 428$ & $\ldots$ & $\ldots$ \\
\hline & Total . & 99 & $168 \cdot 59$ & $\ldots$ & ... & $\ldots$ \\
\hline
\end{tabular}

Since it is possible to distinguish each chromosome type at metaphase $I$, the correlation of any bivalent with any other bivalent for chiasma frequency can be calculated. The results of such an analysis are given in table 6 for both disomic and tetrasomic metaphase I samples. The correlation coefficients for the remaining chromosomes

TABLE 6

Correlation coefficients of the $L$ and $M_{4}$ bivalents in disomic and tetrasomic metaphase I samples

\begin{tabular}{|c|c|c|c|c|c|c|c|c|}
\hline \multirow{2}{*}{ Class } & \multirow{2}{*}{ Sample } & \multirow{2}{*}{$\mathrm{dF}$} & \multicolumn{6}{|c|}{ Bivalent on bivalent correlation } \\
\hline & & & $\mathrm{L}_{1} \mathrm{~L}_{2}$ & $\mathrm{~L}_{1} \mathrm{~L}_{3}$ & $\mathrm{~L}_{1} \mathrm{M}_{4}$ & $\mathrm{~L}_{2} \mathrm{~L}_{3}$ & $\mathrm{~L}_{2} \mathrm{M}_{4}$ & $\mathrm{~L}_{3} \mathrm{M}_{4}$ \\
\hline Disomic & I & 18 & +0.406 & +0.212 & $+0 \cdot 066$ & $+0 \cdot 379$ & $+0 \cdot 199$ & -0.066 \\
\hline Tetrasomic & $\begin{array}{l}3^{\mathrm{a}} \\
3^{\mathrm{b}} \\
4 \\
5^{\mathrm{a}} \\
5^{\mathrm{b}}\end{array}$ & $\begin{array}{r}18 \\
8 \\
8 \\
8 \\
8\end{array}$ & $\begin{array}{r}+0.155 \\
+0.271 \\
0.000 \\
-0.566 \\
+0.149\end{array}$ & $\begin{array}{r}+0.378 \\
-0.452 \\
-0.600 \\
+0.168 \\
0.000\end{array}$ & $\begin{array}{l}+0.142 \\
+0.494 \\
+0.639^{*} \\
+0.168 \\
-0.617\end{array}$ & $\begin{array}{r}+0.132 \\
-0.220 \\
0.000 \\
+0.082 \\
-0.423\end{array}$ & $\begin{array}{r}-0.326 \\
+0.126 \\
0.000 \\
+0.490 \\
+0.069\end{array}$ & $\begin{array}{r}-0.043 \\
-0.100 \\
-0.600 \\
+0.224 \\
0.000\end{array}$ \\
\hline
\end{tabular}

* Significant at the 5 per cent. level.

$\left(M_{5}-M_{7}\right.$ and $\left.S_{8}\right)$ are very small, because these almost invariably form only one chiasma, and for this reason are not included in the table.

Only one correlation coefficient is significant and then only at the 5 per cent. level of probability, and since there are 36 calculations this is to be expected. There also appears to be no pattern in these correlation coefficients. No sample or particular bivalent is consistently positively or negatively correlated; even the $\mathrm{L}_{1} \mathrm{M}_{4}$ positive correlation is offset by a high negative one in the $5 \mathrm{~b}$ sample. 


\section{DISCUSSION}

The existence of, and the conditions within, this chromosomal mosaic has a bearing on two points of interest. First, the mechanism of mitotic non-disjunction and secondly the conditions governing chiasma formation within nuclei.

\section{(i) Non-disjunction}

Mitotic non-disjunction is theoretically possible by one of two methods. On the one hand both sister half centromeres might orientate to the same mitotic pole. Alternatively, if sister half centromeres autoorientate, the regions of special cycle of division may persist undivided through anaphase. These possibilities have never been visibly distinguished: a modified form of the second has been seen in the Bchromosome of rye (Müntzing, 1946), where at the first pollen grain mitotis sister chromatids fail to separate despite the division of both centromeres and regions with special cycle of division. This is because of the existence of two adhesion loci situated equidistant from the centromere.

Whilst the cytological evidence is unsatisfactory, there are some suggestive genetical observations on the behaviour of the centromere at meiosis. Wallace ( $196 \mathrm{I}$ ) has shown that if two distinct inbred lines of mice are crossed, then in the heterozygote the centromeres of similar ancestry tend to move to the same pole. This has been interpreted as implying that genetically similar centromeres, and hence the loci linked closely to them, show an affinity in movement.

This affinity is, of course, a meiotic phenomenon and leads to nonrandom segregation of non-homologous centromeres. Affinity is presumably dependent upon inter-centromeric interaction, and for this reason might operate at mitosis as well as meiosis, though here, of course, it would not be detectable under normal circumstances.

In a normal mitotic cycle sister half-centromeres auto-orientate and move to opposite poles; non-sister half-centromeres of homologous chromosomes move to the same pole. Where mitotic non-disjunction occurs sister half-centromeres behave in an essentially meiotic manner and this may facilitate the detection of intra-centromeric interaction. Whereas meiotic affinity is necessarily between non-homologes the opportunity for interaction between centromeres at mitosis is not so limited. Indeed, since the possibility of close genetic relationship between the homologous centromeres should exceed that between nonhomologous ones, affinity relations at mitosis might be expected to involve homologues preferentially. The absence of trisomic cells in the mosaic indicates that the two non-disjunctional events cannot be separated by more than one mitotic cycle. This means that, either both homologues undergo non-disjunction in the same mitotic sequence, or that one of the three homologous chromosomes produced by single non-disjunction undergoes further non-disjunction at the very next mitotis. 


\section{Plate}

All figs. are from acetic-orcein squash preparations and are reproduced at $c a \times 1500$.

Fig. 1.-The normal diplotene complement of Chorthippus parallelus.

Figs. 2-4. -Tetrasomic cells at diplotene fron the tetra-disomic mosaic. In fig. 4 note the marked heteropycnosity of one of the $M_{1}$-type bivalents which is associated by stickiness with the precocious $\mathbf{M}_{6}$.

FIG. 5.-A tetrasomic cell with an extra X-chromosome at diakinesis. 


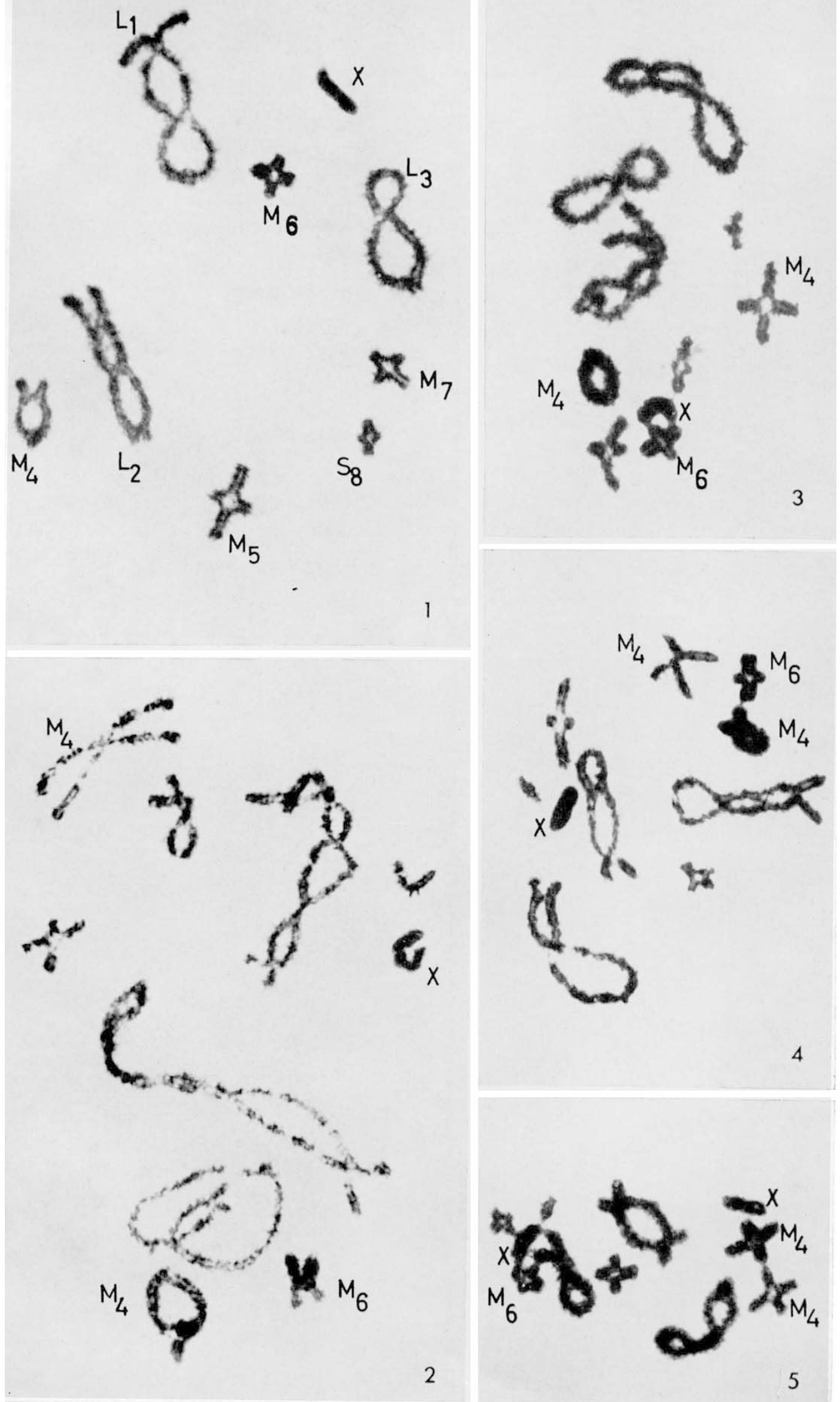


The simplest and most probable interpretation is simultaneous non-disjunction of both homologues. And in this we see, perhaps, the expression of something comparable to meiotic affinity, but acting between homologous rather than non-homologous centromeres and conditioned in this instance by some unique nuclear-cytoplasmic interaction. This suggests also that the centromere of $\mathrm{M}_{4}$ at least is in some way different from the other centromeres.

\section{(ii) Chiasmato conditions within nuclei}

Mather (1936, 1939) showed that in some species bivalents within a nucleus compete for chiasmata. This demonstration depended upon the finding of a negative correlation between chiasma frequencies of different chromosome classes within nuclei. More recently similar demonstrations have been made in Delphinium under normal conditions of chiasma formation (Basak and Jain, 1962), abnormal conditions of chiasma formation leading to the production of univalents (Jain and Basak, 1963) and in interchange heterozygotes (Basak and Jain, in press).

Mather explained this competition in terms of an upper limit in cell chiasma frequency; in those cases where no competition exists this upper limit is not attained. By comparing disomic and trisomic maize Mather was able to show that the addition of an extra chromosome led to an elevation of the upper limit.

In the present case the presence of extra chromosomes does not affect the correlation between bivalents for chiasma frequency. Since, however, the upper limit is not operating even in the disomic cells, then competition is not expected in the tetrasomic ones.

Whilst there is no competition in tetrasomic cells there is an interesting and significant difference between the total cell chiasmata in different samples of the mosaic. This probably reflects a follicle difference in the pattern of mosaicism. Certainly single follicle analysis shows that the chromosome condition within a follicle is constant. Unfortunately it was impossible to obtain sufficient scorable cells from single follicles to investigate the chiasma conditions within follicles. But if this interpretation is correct, it implies that the tetrasomic cells may be more sensitive to differences in developmental background than are disomic cells.

This has an interesting corollary: clearly where multivalent formation does not occur there will be no mechanical obstacle to the production of polysomics in species where, as in Chorthippus, no competition occurs, or where, as in maize, the competitive limit rises on the addition of extra chromosomes. Indeed, the only situation under which an aneuploid would face a chiasma problem is where all the chromosomes in the complement are similar in size and chiasma potential, and where competition already exists at a level which is not increased by polysomy. 
Mechanical difficulties of chromosomal behaviour, therefore, are not likely to be serious, and the fitness of a tetrasomic aneuploid will depend essentially on the physiological effect in development that results from the new and unbalanced condition of the genes.

\section{SUMMARY}

I. In a tetrasomic germ line mosaic of Chorthippus parallelus 75 per cent. of the meiotic cells observed were found to contain an extra autosomal bivalent.

2. With the possible exception of increased pycnosity, the additional chromosomes were indistinguishable in morphology and behaviour from the normal $\mathbf{M}_{4}$ member of the complement. The absence of multivalent formation in tetrasomic cells is not surprising since tetraploid cells of this species rarely form multivalents in the $\mathbf{M}_{4}$ category.

3. The tetrasomic cells are the products of double mitotic nondisjunction at an early stage in the development of the germ line.

4. No competition for chiasmata occurs between bivalents in this species, and the addition of the two extra chromosomes leads to a simple increase in the chiasma potential of the cell.

Acknowledgments. - I am very grateful to $\mathrm{Dr} \mathrm{B}$. John for his help and guidance in this work and to Dr J. L. Jinks for his advice on the statistical methods used. The critical reading of the manuscript by Professor K. Mather is also gratefully acknowledged.

\section{REFERENCES}

BARKER, J. F. 1960. Variation in chiasma frequency in and between natural populations of Acridide. Heredity, 14, 21 1-2 I 4.

BASAK, s. L., AND JAIN, H. K. 1962. Autonomous and interrelated formation of chiasmata in Delphinium chromosomes. Chromosoma (Berl.), 13, 577-587.

BASAK, S. L., AND JAIN, H. K. The interchange distribution of chiasmata in interchange heterozygotes of Delphinium. Heredity, 19.

HENDERSON, s. A. 1961. Chromosome number and behaviour in the grasshopper Pholidoptera. Heredity, $16,18 \mathrm{I}-186$.

JAIN, H. K., AND BASAK, S. L. 1963. Interchromosome effects of chiasmata and crossing-over. Nature, 197, 725-726.

JOHN, B., LEWIS, K. R., AND HENDERSON, S. A. 1960. Chromosome abnormalities in a wild population of Chorthippus brunneus. Chromosoma (Berl.), II, I-2O.

JOHN, B., AND HENDERSON, s. A. 1962. Asynapsis and polyploidy in Schistocerca paranensis. Chromosoma (Berl.), 13, $111-147$.

JOHN, B., AND NAYLOR, B. I961. Anomalous chromosome behaviour in the germ line of Schistocerca gregaria. Heredity, $16,187-198$.

LYon, M. F. 1961. Gene action in the X-chromosome of the mouse (Mus musculus L.). Nature, 190, 372-373.

MATHER, K. 1936. Competition between bivalents during chiasma formation. Proc. Roy. Soc. B, 120, 208-227.

MATHER, K. 1939. Competition for chiasmata in diploid and trisomic maize. Chromosoma, I, I19-129.

MÜNTZING, A. 1946. Cytological studies of extra fragment chromosomes in rye. III. The mechanism of non-disjunction at pollen mitosis. Hereditas, 32, 97-1 19. WAllace, M. E. I961. Affinity: evidence from crossing inbred lines of mice. Heredity, $16, \mathrm{I}-23$. 